\title{
Note
}

\section{Gonadotropin-releasing hormone is prerequisite for the constitutive expression of pituitary annexin A5}

\author{
Tomohiro Yonezawa ${ }^{1), 2)}$, Aiko Watanabe ${ }^{1)}$, Shiro Kurusu ${ }^{1)}$ and Mitsumori Kawaminami ${ }^{1)}$ \\ 1) Laboratory of Veterinary Physiology, School of Veterinary Medicine, Kitasato University, Aomori 034-8628, Japan \\ 2) Current affiliation: Laboratory of Veterinary Clinical Pathology, Graduate School of Agricultural and Life Sciences, The \\ University of Tokyo, Tokyo 113-8657, Japan
}

\begin{abstract}
Annexin A5 (ANXA5), a member of the structurally related family of annexin proteins, is expressed in pituitary gonadotropes. We previously reported that ANXA5 expression is stimulated by gonadotropin-releasing hormone $(\mathrm{GnRH})$. In the present study, we investigated ANXA5 expression in the anterior pituitary gland of GnRH-deficient mutant hypogonadal $(h p g)$ mice. RT-PCR demonstrated that luteinizing hormone $\beta$ subunit (LH $\beta$ ) and ANXA5 mRNA levels were both lower in the pituitary gland of hpg mice than in wild-type mice. Immunohistochemistry showed that ANXA5 expression throughout the pituitary gland was very low in $h p g$ mice, suggesting that ANXA5 is diminished in gonadotropes and also in other cell types. Subcutaneous administration of a GnRH analogue, des-gly10 (Pro9)-GnRH ethylamide (1 $\mu \mathrm{g} /$ day for 7 days), augmented the expression of LH $\beta$ and ANXA5 in the pituitary gland in hpg mice. However, LH $\beta$ - and ANXA5-positive cells did not show exactly matched spatial distributions. These findings suggest that GnRH is necessary for constitutive ANXA5 expression in the pituitary gland, not only in gonadotropes but also in other pituitary gland cell types. A close relationship between ANXA5 and LH $\beta$ expression was confirmed. It is suggested that a significant role of ANXA5 in the physiologic secretion of LH.
\end{abstract}

Key words: Annexin A5 (ANXA5), Gonadotropin-releasing hormone (GnRH), Hypogonadal ( $h p g$ ) mouse, Gene expression

ANNEXIN A5 (ANXA5) is a member of the annexin family of structurally related proteins, which are characterized by calcium-dependent phospholipid binding $[1,2]$. Although found in a variety of tissues, the distribution of ANXA5 is specific to cell type [3, 4]. We previously reported that ANXA5 is expressed in gonadotropes of the anterior pituitary gland and that its expression is enhanced after ovariectomy in rats $[4$, 5]. We also demonstrated that gonadotropin-releasing hormone $(\mathrm{GnRH})$ stimulates ANXA5 synthesis in vivo and in vitro [6,7], indicating the expression of ANXA5 is directly regulated by the GnRH receptor. Finally, we showed that the suppression of ANXA5 synthesis with antisense oligonucleotides retards GnRH-stimulated luteinizing hormone (LH) release [8].

Submitted Jul. 12, 2015; Accepted Sep. 8, 2015 as EJ15-0410 Released online in J-STAGE as advance publication Oct. 3, 2015 Correspondence to: Mitsumori Kawaminami, Laboratory of Veterinary Physiology, School of Veterinary Medicine, Kitasato University, Aomori 034-8628, Japan.

E-mail: mitsumor@vmas.kitasato-u.ac.jp

(C) The Japan Endocrine Society
Hypogonadal ( $h p g$ ) mutant mice have a truncation in the gene encoding GnRH-associated peptide, leading to the absence of GnRH translation [9]. GnRH deficiency results in very low levels of gonadotropins and infertility $[10,11]$. The incompletely developed genital tract of $h p g$ mice is restored by the administration of exogenous GnRH [12], indicating an intact GnRH receptor system in hpg mice. Thus, the hpg mouse is a useful animal model for studying exogenous GnRH action with no background of endogenous GnRH.

In this study, we investigated the expression of ANXA5 in the anterior pituitary gland of $h p g$ mice and observed changes in its expression after $\mathrm{GnRH}$ analogue (GnRHa) administration.

\section{Materials and Methods}

All experiments were approved by the Animal Experiments Ethics Committees of Kitasato University. Mutant hpg mice were obtained from Jackson Laboratory. Mice were maintained in a room with a 
14/10-h light/dark cycle and fed standard rodent chow. Heterozygous mice were mated to generate homozygous hpg mice. Genotypes were determined using a standard PCR procedure with the following primers: hpg Gnrh gene, 5'-AGT CTC TTC CCA GGT GAT T-3' (forward) and 5'-TTC CAG GTT TCA GTG CAT C-3' (reverse) (product size: $324 \mathrm{bp}$ ); wild-type (WT) Gnrh gene, 5'-AAT CAA TCC AAC CTC GCT G-3' (forward) and 5'-GAA TGA GCT GGA GTT TAG G-3' (reverse) (product size: $693 \mathrm{bp}$ ). Adult homozygous hpg mice and their WT littermates were used for all experiments.

Pituitary glands of $h p g$ and WT mice $(\mathrm{n}=3$ per group) were collected immediately after decapitation for reverse transcription (RT)-PCR analysis of LH $\beta$ and ANXA5 expression. Pituitary glands were submerged in extraction solution (TRIzol, Invitrogen, Carlsbad, CA), and total RNA was extracted from the tissues according to the manufacturer's instructions. The concentration of total RNA was measured by ultraviolet spectrophotometry. Total RNA (500 ng) was reversetranscribed for each sample using a standard reverse transcription kit (Multiscribe High Capacity cDNA Reverse Transcription Kits, Applied Biosystems, Foster City, CA) with random primers according to the manufacturer's instructions. RT-PCR was performed using a Veriti Thermal Cycler (Applied Biosystems). The primers were designed as follows: LH $\beta, 5^{\prime}$-TGG AGA GGC TCC AGG GGC TG-3' (forward) and 5'-GGG GAG GTG GGG GAG GTC AC-3' (reverse) (product size: $407 \mathrm{bp}$ ); ANXA5, 5'-AGA TGA TGT GGT GGG GGA TA-3' (forward) and 5'-TCT CTG CAA GGT AGG CAG GT-3' (reverse) (product size: 342 bp); ribosomal RNA RPL19 as the internal control, 5'-CTG ATC AAG GAT GGG CTG AT-3' (forward) and 5'-TTC AGC TTG TGG ATG TGC TC-3' (reverse) (product size: 308 bp). Each RT-PCR reaction used $0.4 \mu \mathrm{L}$ forward primer (final concentration: 2 $\mu \mathrm{M}), 0.4 \mu \mathrm{L}$ reverse primer, $10 \mu \mathrm{L}$ Premix Taq reagent (Takara Shuzo, Shiga, Japan), and 7.2 $\mu \mathrm{L}$ nucleasefree water. The thermal cycling conditions were $95^{\circ} \mathrm{C}$ for $5 \mathrm{~min}$ for preincubation; $24-28$ cycles at $94^{\circ} \mathrm{C}$ for $30 \mathrm{~s}, 58-64^{\circ} \mathrm{C}$ for $30 \mathrm{~s}$, and $72^{\circ} \mathrm{C}$ for $1 \mathrm{~min}$; and $72^{\circ} \mathrm{C}$ for $5 \mathrm{~min}$ for postincubation. After electroplating, the intensities of each band were measured using densitometry analysis (ImageJ 1.42q, National Institutes of Health, Bethesda, MD). The mRNA levels of LH $\beta$ and ANXA5 were normalized to that of RPL19.

For fluorescent immunohistochemistry, adult $h p g$ and WT mice ( $n=3-6$ per group) were killed by anesthetic overdose of diethyl ether and intracardiac perfusion of $4 \%$ buffered paraformaldehyde $(30 \mathrm{~mL})$. Pituitaries were removed and postfixed overnight. Paraffin sections (4 $\mu \mathrm{m}$ thick) were processed for immunohistochemistry. Primary antibodies were monoclonal anti-human ANXA5 (Anti-ANXA5, dilution: 1:5,000; Kowa, Aichi, Japan) and rabbit anti-rat LH $\beta$ (Anti-LH $\beta$, dilution 1:10,000; NIDDK (Bethesda, MD, USA)). Dried sections were processed through a series of xylene and ethanol rinses to replace the paraffin with water. Following a blocking treatment of $1 \%$ normal goat serum for $1 \mathrm{~h}$ at room temperature, incubation with a primary antibody was performed at $4^{\circ} \mathrm{C}$ in a humidified atmosphere overnight. Secondary antibodies were Alexa 488 goat anti-mouse IgG (1:10,000; Invitrogen, Carlsbad, CA) or Alexa 568 goat anti-rabbit IgG (1:10,000; Invitrogen). Sections were observed by confocal microscopy (LSM710, Carl Zeiss, Freistaat Thüringen, Germany). Normal rabbit or mouse serum was used instead of a primary antibody for the negative control, which showed no signal under the same conditions.

For bright-field immunohistochemistry, sections were incubated with $2.5 \%$ normal horse serum for 30 min to reduce non-specific antibody binding. The primary antibody was anti-ANXA5 rabbit serum raised in our laboratory [13]. The antiserum was diluted to $1: 10,000$, and sections were incubated with the serum overnight at $4{ }^{\circ} \mathrm{C}$. The secondary antibody was from the Immpress reagent anti-rabbit IgG POD kit (Vector Laboratories, Burlingame, CA). Sections were counterstained with hematoxylin.

In one experiment, GnRH agonist (GnRHa) or saline was subcutaneously administered to adult $h p g$ mice ( $\mathrm{n}=4$ per group). The GnRHa (des-gly 10 (Pro9)GnRH ethylamide; $1.0 \mu \mathrm{g} / 0.2 \mathrm{~mL})$ or saline $(0.2 \mathrm{~mL})$ was injected once a day for 7 days. Pituitaries were collected $3 \mathrm{~h}$ after the last injection.

RT-PCR results were analyzed using Student's $t$-tests. A $p$-value $<0.05$ was considered statistically significant.

\section{Results and Discussion}

We found that the expression of LH $\beta$ and ANXA5 mRNA in the pituitary gland of $h p g$ mice compared with that of WT mice (Fig. 1A-B), which was expected based on previous findings [9]. In earlier studies, we demonstrated that GnRH directly stimulates the expression of ANXA5 in primary cultures of pituitary cells and the gonadotrope cell line L $\beta \mathrm{T} 2[6,7]$. The 
A
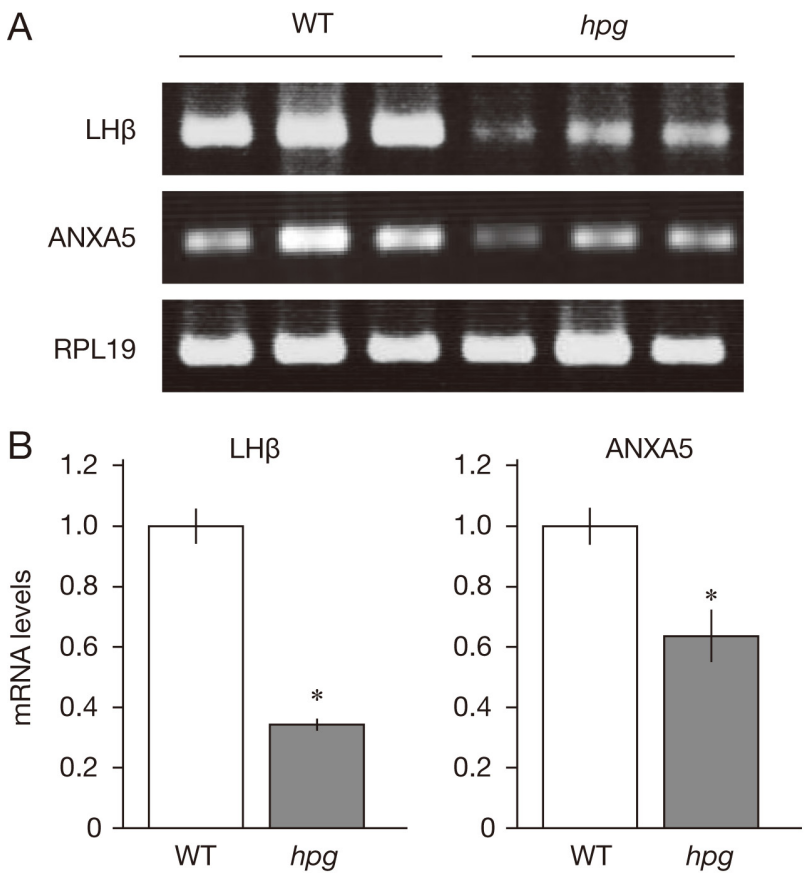

Fig. 1 RT-PCR analysis of LH $\beta$ and ANXA5 mRNA levels in WT and hpg mice. (A) DNA products in an agarose gel visualized with ethidium bromide. RPL19 is a ribosomal RNA used as an internal control. (B) Each band was scanned, and its density was measured using ImageJ. Intensity was normalized to that of RPL19. Data are shown as mean \pm standard error of the mean $(\mathrm{n}=3$ per group). ${ }^{*} p<0.05$.

A

WT
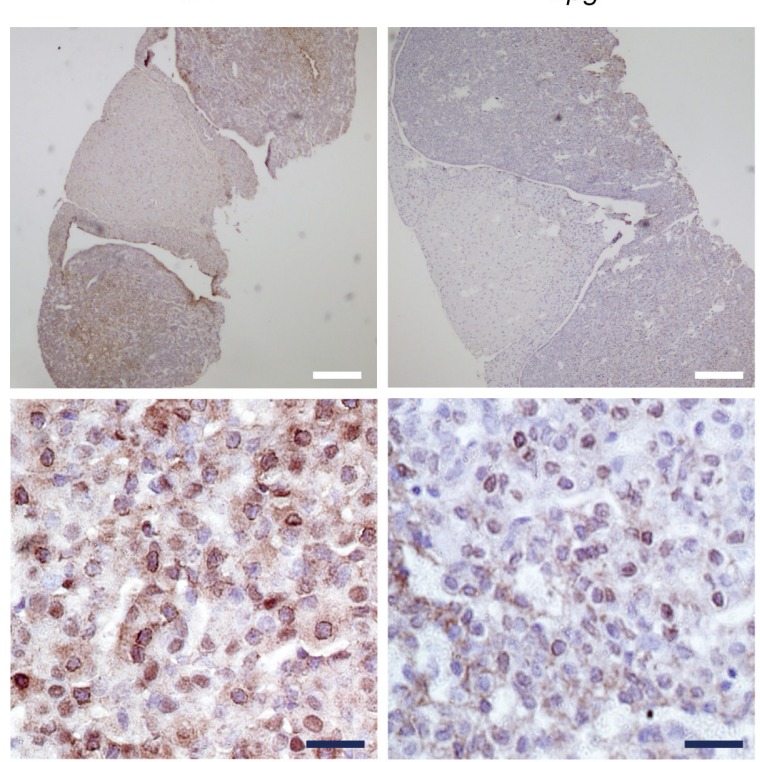

present results, therefore, indicate that basal ANXA5 synthesis in the pituitary gland is maintained by constitutive GnRH stimulation. Immunohistochemistry revealed a low expression of ANXA5 throughout the anterior pituitary gland of $h p g$ mice (Fig. 2A-B). As gonadotropes comprise approximately $10 \%$ of pituitary gland cells [14], other hormone-secreting cells apart from gonadotropes may contribute to this reduction of ANXA5. Although further studies are needed, it is possible that gonadotropes are the primary cell type responsible for supplying ANXA5 in the pituitary gland. Alternatively, as the $\mathrm{GnRH}$ receptor is found not only in gonadotropes but also lactotropes [15], GnRH could also act through this cell type. If this is the case, GnRH could affect the function of lactotropes through ANXA5 synthesis, as GnRH has been shown to modify prolactin secretion [16].

The annexin family is made up of 12 structurally related proteins (ANXA1 to 13, ANXA12 is not assigned) in mammals. The annexin molecule consists of four repeats of an approximately 60 amino acid conserved sequence (eight repeats in ANXA6) and a variable N-terminal sequence [17]. The N-terminal sequence is thought to serve a specific function for each annexin, although the N-terminus of ANXA5 is missing [17]. Despite these interesting biochemical

B

WT

hpg
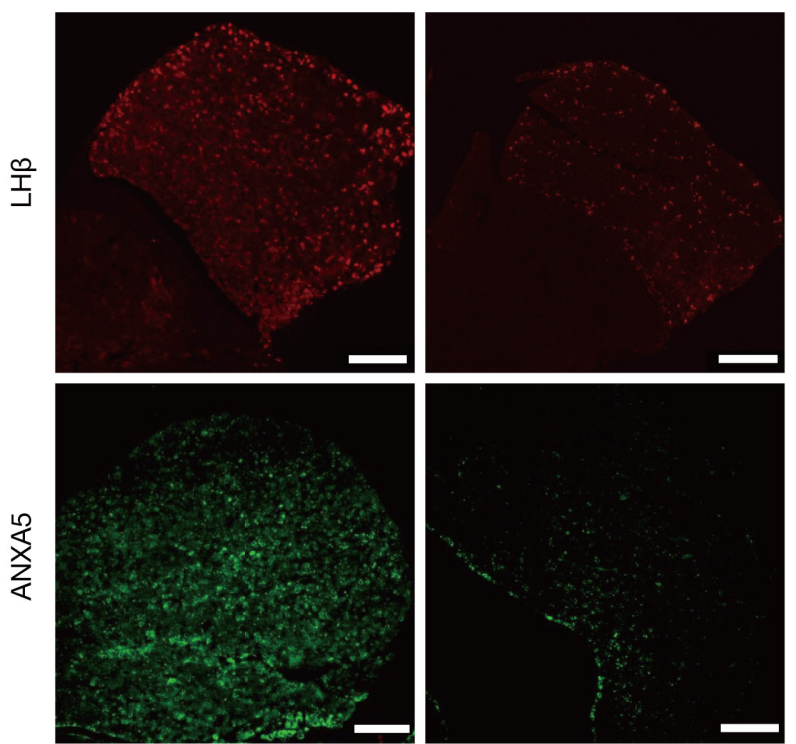

Fig. 2 Immunohistochemistry analysis of LH $\beta$ and ANXA5 expression in WT and hpg mice. (A) Bright-field images of pituitary tissue. Brown-black staining indicates ANXA5 immunoreactivity. Sections were counterstained with hematoxylin. (B) Fluorescent images of anterior pituitary tissue. Red and green signals indicate LH $\beta$ and ANXA5 immunoreactivity, respectively. Scale bars: $200 \mu \mathrm{m}$. 
A

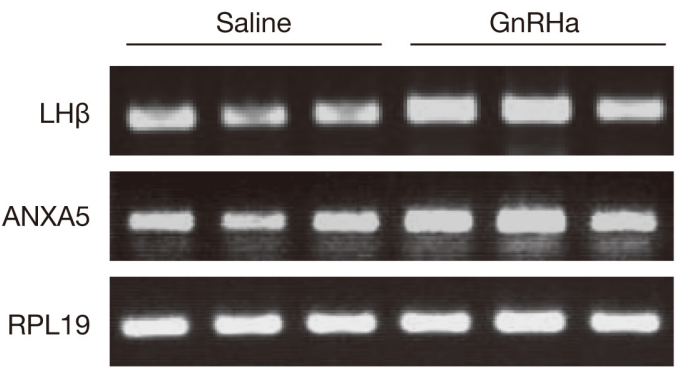

B
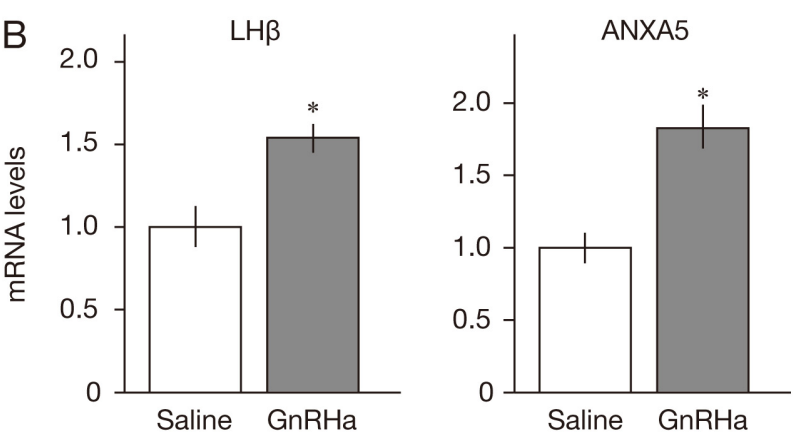

Fig. 3 RT-PCR analysis of the effect of GnRHa administration on LH $\beta$ and ANXA5 mRNA levels in hpg mice. (A) DNA products in an agarose gel visualized with ethidium bromide. Saline or GnRHa was subcutaneously administered daily for 7 days. (B) Each band was scanned, and its density was measured using ImageJ. Intensity was normalized to that of RPL19. Data are shown as mean \pm standard error of the mean $(n=3$ per group). $* p<0.05$.
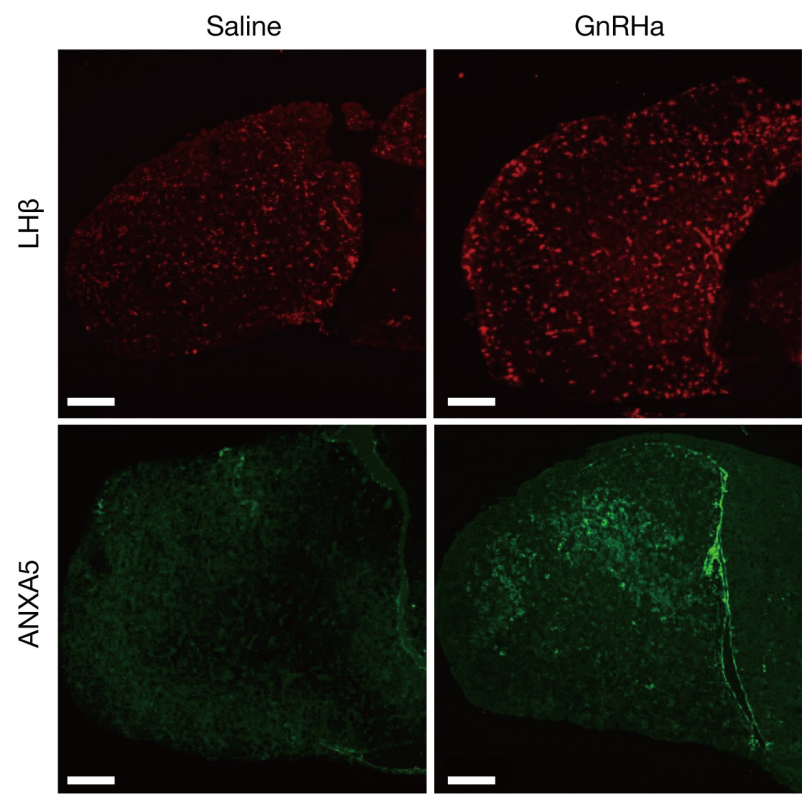

Fig. 4 Immunohistochemistry analysis of LH $\beta$ and ANXA5 expression in saline- or GnRHa-treated hpg mice. Fluorescent images of anterior pituitary tissue. Green signal indicates ANXA5 immunoreactivity. Scale bars: $100 \mu \mathrm{m}$. characteristics, the physiological function of annexins is not well elucidated. Previous studies indicate that ANXA1 mediates the anti-inflammatory effects of glucocorticoids by inhibiting phospholipase $\mathrm{A}_{2}[18,19]$, and ANXA 7 is related to the release of secretory granules in adrenal medulla cells [20]. Among all annexins, however, ANXA5 has been the best studied. Since its discovery, ANXA5 has been postulated to suppress blood coagulation in pregnant woman [21]. We recently showed that ANXA5 deficiency increases placental thrombosis and pregnancy loss in ANXA5-null mice [22]. Although we do not know whether placental ANXA5 expression is induced by local GnRH, we previously demonstrated an intimate relationship between GnRH and ANXA5 in tissues other than the anterior pituitary gland. Specifically, we found that ovarian GnRH increases ANXA5 expression and apoptosis in the corpus luteum [23], and testicular GnRH stimulates ANXA5 synthesis in Leydig cells [24]. These results suggest that ANXA5 is involved in basic cell functions such as cell growth rather than serving a gonadotropespecific function. However, although ANXA5 seems to have multiple functions in various tissues, future studies are expected to show a consistent function of ANXA5 in gonadotropin secretion, inhibition of blood coagulation, apoptosis, and cell cycle.

Next, we found that administration of GnRHa for 7 days significantly increased LH $\beta$ and ANXA5 mRNA levels in the pituitary gland of $h p g$ mice (Fig. 3A-B), suggesting that ANXA5 expression is sustained by $\mathrm{GnRH}$ in wild mouse. Immunohistochemistry also showed that GnRH-stimulated LH $\beta$ and ANXA5 expression (Fig. 4). Not only the intensity of the LH $\beta$ signal but also the area of $\mathrm{LH} \beta$-positive cells was increased after GnRHa administration. As GnRH stimulates the proliferation of gonadotropes [25], it appears that $\mathrm{GnRH}$ increases the number of gonadotropes in the pituitary gland of $h p g$ mice.

Differences in the spatial distribution of ANXA5 and LH $\beta$ (Fig. 4) suggest the abundance of ANXA5positive but LH $\beta$-negative cells in the pituitary gland of $h p g$ mice after GnRHa administration. Furthermore, the distribution of ANXA5 in GnRHa-treated $h p g$ mice differed from that of untreated WT mice (Fig. 2B), suggesting that normal secretion of GnRH in WT mice regulates ANXA5 expression differently than repetitive administration of GnRHa in $h p g$ mice. GnRHa administration has been suggested to facilitate gonadotropin secretion, and thus ANXA5 synthesis may pre- 
cede LH $\beta$ synthesis in premature gonadotropes. Also, ANXA5 has been postulated to be involved in cell cycle-related phenomena [26] and apoptosis [23].

The results of the present study demonstrate that ANXA5 expression is supported by secretion of hypothalamic $\mathrm{GnRH}$ and suggest a close relationship between gonadotropin synthesis and ANXA5 expression. Thus, ANXA5 could serve to regulate the physiologic secretion of LH.

\section{Acknowledgments}

Support for this project was provided by a Grantin-Aid for Young Scientists (B, 22780263) from the Japan Society for the Promotion of Science (JSPS) and a Kitasato University Research Grant for Young Researchers and Encouragement of Young Scientists to TY. This work was also partly supported by JSPS Grantin-Aid for Scientific Research to MK (26660252).

\section{References}

1. Crompton MR, Owens RJ, Totty NF, Moss SE, Waterfield MD, et al. (1988) Primary structure of the human, membrane-associated $\mathrm{Ca} 2+$-binding protein p68 a novel member of a protein family. EMBO $J$ 7: 21-27.

2. Walker JH, Boustead CM, Koster JJ, Bewley M, Waller DA (1992) Annexin V, a calcium-dependent phospholipid-binding protein. Biochem Soc Trans 20: 828-833.

3. Giambanco I, Pula G, Ceccarelli P, Bianchi R, Donato $R$ (1991) Immunohistochemical localization of annexin $\mathrm{V}(\mathrm{CaBP} 33)$ in rat organs. J Histochem Cytochem 39: 1189-1198.

4. Kawaminami M, Kawamoto T, Tanabe T, Yamaguchi K, Mutoh K, et al. (1998) Immunocytochemical localization of annexin 5, a calcium-dependent phospholipid-binding protein, in rat endocrine organs. Cell Tissue Res 292: 85-89.

5. Kawaminami M, Yamaguchi K, Miyagawa S, Numazawa S, Ioka H, et al. (1998) Ovariectomy enhances the expression and nuclear translocation of annexin 5 in rat anterior pituitary gonadotrophs. Mol Cell Endocrinol 141: 73-78.

6. Kawaminami M, Tsuchiyama Y, Saito S, Katayama M, Kurusu S, et al. (2002) Gonadotropin-releasing hormone stimulates annexin 5 messenger ribonucleic acid expression in the anterior pituitary cells. Biochem Biophys Res Commun 291: 915-920.

7. Kawaminami M, Uematsu N, Funahashi K, Kokubun R, Kurusu S (2008) Gonadotropin releasing hormone $(\mathrm{GnRH})$ enhances annexin A5 mRNA expression through mitogen activated protein kinase (MAPK) in LbetaT2 pituitary gonadotrope cells. Endocr $J$ 55: 1005-1014.

8. Kawaminami M, Etoh S, Miyaoka H, Sakai M, Nishida $\mathrm{M}$, et al. (2002) Annexin 5 messenger ribonucleic acid expression in pituitary gonadotropes is induced by gonadotropin-releasing hormone $(\mathrm{GnRH})$ and modulates GnRH stimulation of gonadotropin release. Neuroendocrinology 75: 2-11.

9. Cattanach BM, Iddon CA, Charlton HM, Chiappa SA, Fink G (1977) Gonadotrophin-releasing hormone defi- ciency in a mutant mouse with hypogonadism. Nature 269: 338-340.

10. Mannan MA, O’Shaughnessy PJ (1988) Ovarian steroid metabolism during post-natal development in the normal mouse and in the adult hypogonadal ( hpg) mouse. $J$ Reprod Fertil 82: 727-734.

11. O'Shaughnessy PJ, Mannan MA (1994) Development of cytochrome P-450 side chain cleavage mRNA levels in neonatal ovaries of normal and hypogonadal $(\mathrm{hpg})$ mice. Mol Cell Endocrinol 104: 133-138.

12. Charlton HM, Halpin DM, Iddon C, Rosie R, Levy G, et al. (1983) The effects of daily administration of single and multiple injections of gonadotropin-releasing hormone on pituitary and gonadal function in the hypogonadal (hpg) mouse. Endocrinology 113: 535-544.

13. Takehara K, Uchida S, Marumoto N, Asawa T, Osugi $S$, et al. (1994) Secretion of recombinant rat annexin 5 by insect cells in a baculovirus expression system. Biochem Biophys Res Commun 200: 1421-1427.

14. Ibrahim SN, Moussa SM, Childs GV (1986) Morphometric studies of rat anterior pituitary cells after gonadectomy: correlation of changes in gonadotropes with the serum levels of gonadotropins. Endocrinology 119: 629-637.

15. Mertani HC, Testart C, Ouhtit A, Brisson C, Morel G (1996) Gonadotropin-releasing hormone receptor gene expression in rat anterior pituitary. Endocrine 4: 159163.

16. Rivier C, Vale W (1982) Interaction of gonadotropinreleasing hormone agonist and antagonist with progesterone, prolactin, or human chorionic gonadotropin during pregnancy in the rat. Endocrinology 110: 347-351.

17. Laohavisit A, Davies JM (2011) Annexins. New Phytol 189: 40-53.

18. Goulding NJ, Guyre PM (1993) Glucocorticoids, lipocortins and the immune response. Curr Opin Immunol 5: 108-113.

19. Flower RJ, Rothwell NJ (1994) Lipocortin-1: cellular mechanisms and clinical relevance. Trends Pharmacol Sci 15: 71-76.

20. Kuijpers GA, Lee G, Pollard HB (1992) 
Immunolocalization of synexin (annexin VII) in adrenal chromaffin granules and chromaffin cells: evidence for a dynamic role in the secretory process. Cell Tissue Res 269: 323-330.

21. Masuda J, Takayama E, Satoh A, Ida M, Shinohara T, et al. (2004) Levels of annexin IV and V in the plasma of pregnant and postpartum women. Thromb Haemost 91: 1129-1136.

22. Ueki H, Mizushina T, Laoharatchatathanin T, Terashima R, Nishimura Y, et al. (2012) Loss of maternal annexin A5 increases the likelihood of placental platelet thrombosis and foetal loss. Sci Rep 2: 827.

23. Kawaminami M, Shibata Y, Yaji A, Kurusu S, Hashimoto I (2003) Prolactin inhibits annexin 5 expression and apoptosis in the corpus luteum of pseudopreg- nant rats: involvement of local gonadotropin-releasing hormone. Endocrinology 144: 3625-3631.

24. Yao B, Kawaminami M (2008) Stimulation of annexin A5 expression by gonadotropin releasing hormone $(\mathrm{GnRH})$ in the Leydig cells of rats. J Reprod Dev 54: 259-264.

25. Lewy H, Ashkenazi IE, Naor Z (2003) Gonadotropin releasing hormone $(\mathrm{GnRH})$ and estradiol (E(2)) regulation of cell cycle in gonadotrophs. Mol Cell Endocrinol 203: 25-32.

26. Klement K, Melle C, Murzik U, Diekmann S, Norgauer J, et al. (2012) Accumulation of annexin A5 at the nuclear envelope is a biomarker of cellular aging. Mech Ageing Dev 133: 508-522. 